\title{
Stimulation of Root Growth Induced by Aluminum in Quercus serrata Thunb. Is Related to Activity of Nitrate Reductase and Maintenance of IAA Concentration in Roots
}

\author{
Rie Tomioka', Chisato Takenaka', Masayoshi Maeshima ${ }^{1}$, Takafumi Tezuka1, Mikiko Kojima², \\ Hitoshi Sakakibara ${ }^{2}$ \\ ${ }^{1}$ Graduate School of Bioagricultural Sciences, Nagoya University, Nagoya, Japan; ${ }^{2}$ RIKEN Plant Science Center, Yokohama, Japan. \\ Email: tomiokar@agr.nagoya-u.ac.jp
}

Received August 10 $0^{\text {th }}, 2012$; revised September $24^{\text {th }}, 2012$; accepted October $16^{\text {th }}, 2012$

\begin{abstract}
Aluminum (Al) is the most abundant metal in the earth's crust. Excess $\mathrm{Al}^{3+}$ released by soil acidification in soil solution is thought to be a growth limiting factor to many cultivated plant species, but it has been reported to stimulate plant growth in some crop and tree species in certain concentration of $\mathrm{Al}^{3+}$. Previously, we had reported that $\mathrm{Al}$ treatment enhanced root development, $\mathrm{NO}_{3}^{-}$uptake from growth media and in vivo nitrate reductase (NR) activity of roots. NR is one of the key enzymes in nitrogen metabolism and acts at the first step of nitrate assimilation in plants. In this study, we investigated the process of Al-induced root development in an early stage, focusing on the change in in vitro NR activity, and indole-3-acetic acid (IAA) and cytokinins concentration in roots of Quercus serrata seedlings, which were treated for $1 \mathrm{~h}$ with $\mathrm{Al}$ or $\mathrm{Ca}$. In Al-treated roots, NR activity increased and IAA concentration was maintained at the same level as pretreatment, and indole-3-acetyl-L-aspartic acid (IA-Asp), which is a metabolic intermediate of IAA degradation, was not detected in roots. In Ca-treated roots, NR activity increased, but IAA concentration decreased as IA-Asp concentration increased. Thus, the maintenance of IAA concentration in Al-treated roots seems to result from suppression in the process of IAA decomposition. Al treatment increased the length and number of second lateral roots but $\mathrm{Ca}$ treatment did not. We concluded that root development induced by $\mathrm{Al}$ in the early stage was related to NR activity and maintenance of IAA concentration.
\end{abstract}

Keywords: Aluminum; Root; Development; NR; IAA; Quercus serrata

\section{Introduction}

Aluminum (Al), a component of primary and clay minerals, is the most abundant metal element on the planet, comprising about $7 \%$ by mass of the earth's crust. Al is released from the solid phase by soil acidification, and exchangeable $\mathrm{Al}$ increases when the $\mathrm{pH}$ of soil solution falls below 5.0. At a $\mathrm{pH}$ of less than 4.0, Al exists predominantly as $\mathrm{Al}^{3+}$. Excess $\mathrm{Al}^{3+}$ in soil solution is considered to be toxic to cultivated plant species and is a limiting factor for plant growth in acidic soil. The $\mathrm{pH}$ of rhizospheric soil around the roots is lower than that of the bulk soil due to release of $\mathrm{H}^{+}$and organic anions from the roots, accompanied by the uptake of cations and respiration. Under these conditions, the concentration of $\mathrm{Al}^{3+}$ around the roots is thought to be higher than that of the average of the bulk soil [1-4]. Therefore, most plant roots are thought to be exposed to high concentrations of $\mathrm{Al}^{3+}$. Although there are many reports about negative effects of Al on plant growth in both crop and tree species, enhancement of growth by Al treatment was reported much less than that and only a few in both crops and trees [5-9], and there seems to be an optimum concentration of $\mathrm{Al}$ for each plant species. Although much information on the mechanism of Al toxicity and Al tolerance in plants has been published [10,11], few reports have focused on the role of $\mathrm{Al}$ in plant growth.

Previously, we reported that Al enhanced root growth in Quercus serrata Thunb. seedlings in experiments with various Al treatments, and suggested that $\mathrm{Al}$ might act as a trigger to induce root elongation and rooting at $1.0 \mathrm{mM}$ and $2.5 \mathrm{mM}$ [7]. Then we showed that $\mathrm{Al}$ enhancement of root growth is related to stimulation of $\mathrm{NO}_{3}^{-}$uptake and activation of in vivo nitrate reductase (NR) in roots 
[12]. Recently, lateral root development induced by NO has been reported to be related to auxin signaling and NR activity for Lycopersicon esculentum [13] and Arabidopsis thaliana [14]. Therefore, we considered that NR activity and auxin might be a key factor in Al-enhanced root growth in $Q$. serrata. In our previous study, stimulation of $\mathrm{NO}_{3}^{-}$uptake and an increase in the number of lateral root primordia were observed in plants 3 days after $\mathrm{Al}$ treatment, but no increase in NR activity in roots measured by an in vivo system was detected after 3 days [12]. NR activity could not be detected possibly because in an in vivo system NR activity is measured according to the final amount of $\mathrm{NO}_{2}^{-}$after some consumption through the metabolic processes in root cells.

Phytohormones, especially indole-3-acetic acid (IAA) and cytokinins, are key factors in the regulation of plant growth, including root development $[15,16]$. We hypothesize that Al may act as an activator of NR in root cells and as a trigger to change the concentration of phytohormones such as auxin and cytokinin, which induce root development, in roots. Therefore to clarify the process/mechanism of Al-induced root development in an early stage, roots were treated with $\mathrm{Al}$ for $1 \mathrm{~h}$ to observe the change of in vitro NR activity, the concentrations of IAA and cytokinins, and root morphogenesis.

\section{Materials and Methods}

\subsection{Plant Materials}

Seeds of Q. serrata were collected from a secondary forest at Nagoya University, Japan. Seeds were germinated in siliceous sand. After root germination, seedlings were grown hydroponically in a modified version of the 1/10 Hoagland's No. 2 nutrient solution, containing $0.6 \mathrm{mM}$ $\mathrm{KNO}_{3}, 0.4 \mathrm{mM} \mathrm{Ca}\left(\mathrm{NO}_{3}\right)_{2} \cdot 4 \mathrm{H}_{2} \mathrm{O}, 0.2 \mathrm{mM} \mathrm{MgSO}{ }_{4} \cdot 7 \mathrm{H}_{2} \mathrm{O}$, $0.1 \mathrm{mM} \mathrm{NH} \mathrm{H}_{2} \mathrm{PO}_{4}, 45.5 \mu \mathrm{M} \mathrm{MnCl}_{2} \cdot 4 \mathrm{H}_{2} \mathrm{O}, 8.95 \mu \mathrm{M}$ $\mathrm{FeCl}_{3} \cdot 6 \mathrm{H}_{2} \mathrm{O}, 0.4 \mu \mathrm{M} \mathrm{ZnSO} \cdot 7 \mathrm{H}_{2} \mathrm{O}, 0.15 \mu \mathrm{M} \mathrm{CuSO}_{4} \cdot 5 \mathrm{H}_{2} \mathrm{O}$, $2.3 \mu \mathrm{M} \mathrm{H}_{3} \mathrm{BO}_{3}$, and $0.25 \mu \mathrm{M} \mathrm{NaMoO}_{4} \cdot 2 \mathrm{H}_{2} \mathrm{O}$ in a growth chamber at $23^{\circ} \mathrm{C}$ with $65 \%$ relative humidity, in a photoperiod of $14 \mathrm{~h} / 10 \mathrm{~h}$ (day/night) and irradiation of 150 $\mu \mathrm{mol} \cdot \mathrm{m}^{-2} \cdot \mathrm{s}^{-1}$ for 8 weeks. The nutrient solution was changed once a week and the $\mathrm{pH}$ of the solution was adjusted to $4.0 \pm 0.1$ with $1 \mathrm{~N} \mathrm{HCl}$.

\subsection{Al Treatment of Seedlings}

Roots of 8-week-old seedlings were exposed to $2.5 \mathrm{mM}$ $\mathrm{AlCl}_{3}\left(\mathrm{pH} \mathrm{4.0)}\right.$ or $4.2 \mathrm{mM} \mathrm{CaCl}_{2}(\mathrm{pH} \mathrm{4.0)}$ solution for $1 \mathrm{~h}$, which was then replaced with freshly prepared nutrient solution. Roots were collected from seedlings before treatment and 1,2, and 3 days after the 1-h treatment. 15 seedlings were collected in each treatment at each sampling time, and $5 \mathrm{~cm}$ from the tip of the first lateral roots and the whole tissue of the second lateral roots were collected and used for further analyses.

\subsection{Enzyme Extraction and Assay of NR Activity}

For preparation of enzyme fractions, all subsequent steps were carried out at $0^{\circ} \mathrm{C}$ to $4^{\circ} \mathrm{C}$. Roots were homogenized in a mortar with a grinding medium composed of $50 \mathrm{mM}$ tris(hydroxymethyl)aminomethane (Tris- $\mathrm{HCl}, \mathrm{pH}$ 7.5), $10 \mathrm{mM}$ Ethylenediaminetetraacetic acid tetrasodium ( $\mathrm{Na}_{2}$-EDTA), $5 \mathrm{mM}$ dithiothreitol (DTT), $1 \%$ bovine serum albumin $(\mathrm{v} / \mathrm{v}), 20 \mu \mathrm{M}$ p-amidinophenyl methanesulfonyl fluoride hydrochloride (p-APSMF), and 50\% [wt/wt] polyvinylpolypyrorolidone (Polyclar AT). The homogenates were filtered with a layer of Miracloth (Calibiochem-Novabiochem, San Diego, CA, USA). The filtrate was centrifuged at $15,000 \mathrm{~g}$ for $10 \mathrm{~min}$. The supernatant was applied to a Sephadex-G25 column (GE Healthcare Bio-Sciences, Uppsala, Sweden; gel volume, $5 \mathrm{ml}$ ) equilibrated with $50 \mathrm{mM}$ Tris- $\mathrm{HCl}(\mathrm{pH} 7.5), 1 \mathrm{mM}$ $\mathrm{Na}_{2}$-EDTA, $5 \mathrm{mM}$ DTT, and $20 \mu \mathrm{M}$ p-APSMF. The protein (enzyme)-rich flow through fractions was collected and used for the NR assay.

NR activity was measured by a modified version of the method of Hageman \& Reed [17] as follows. The reaction mixture $(1 \mathrm{ml})$ containing $23 \mathrm{mM} \mathrm{K}_{3} \mathrm{PO}_{4}(\mathrm{pH} 7.5)$, $4.5 \mathrm{mM} \mathrm{KNO}_{3}, 9 \mu \mathrm{M}$ flavin adenine dinucleotide (FAD), $69 \mu \mathrm{M}$ nicotinamide adenine dinucleotide reduced (NADH), and enzyme fraction was incubated at $30^{\circ} \mathrm{C}$ for $30 \mathrm{~min}$ in the dark. The reaction was stopped by adding $0.1 \mathrm{ml}$ of the $0.5 \mathrm{M}$ zinc acetate. Then the mixture was centrifuged at $5000 \mathrm{~g}$ for $5 \mathrm{~min}$. An aliquot $(0.75 \mathrm{ml})$ of the supernatant was mixed with $16 \mu 1$ of $0.15 \mathrm{mM}$ phenazine methosulfate (PMS) and incubated at $25^{\circ} \mathrm{C}$ for $20 \mathrm{~min}$. Then, $0.5 \mathrm{ml}$ of $1 \%$ sulfanilamide (in $1.5 \mathrm{M} \mathrm{HCl}$ ) and $0.5 \mathrm{ml}$ of $0.02 \% \mathrm{~N}-1$-naphthyl ethylenediamine dihydrochloride were added to the incubated solution. After incubation at $25^{\circ} \mathrm{C}$ for $20 \mathrm{~min}$, absorbance at $540 \mathrm{~nm}$ of the sample was measured using a spectrophotometer (model U-3310, Hitachi, Tokyo, Japan). NR activity on a fresh weight (fw) basis was calculated.

\subsection{Extraction and Quantification of Phyto-Hormones}

The roots were collected from 15 seedlings before treatment and 1,2, and 3 days after the 1-h treatment, as mentioned above. Plant hormones such as IAA and cytokinins in root tissues were extracted and quantified using a liquid chromatography-tandem mass chromatography system (Waters; AQUITY UPLC System/Quattro Ultima $\mathrm{Pt}$ ), as described previously [18]. Also, the amount of indole-3-acetyl-L-alanine (IA-Ala), indole-3-acetyl-L- 
aspartic acid (IA-Asp), indole-3-acetyl-L-iso-leucine (IAIle), indole-3-acetyl-L-leucine (IA-Leu) and indole-3acetyl-L-phenylalanine (IA-Phe), which are a metabolic intermediate of degradation of IAA, was determined to assess turnover of IAA.

\subsection{Root Morphogenesis}

The lengths of the first and second lateral roots were measured before, 3 and 7 days after the 1-h treatment and the numbers of second lateral roots were counted 7 days after the 1-h treatment by LIA 32 software [19].

\section{Results}

The lengths of first and second lateral roots did not change 3 days after 1-h treatment with $\mathrm{Al}$ or $\mathrm{Ca}$ (data not shown). At 7 days after treatment, the length and number of Al-treated second lateral roots were significantly increased compared with those of pretreatment and $\mathrm{Ca}$ treated roots (Table 1).

The in vitro NR activity gradually increased to $175 \%$ on day 3 after 1-h treatment with both $\mathrm{Al}$ and $\mathrm{Ca}$ compared with pretreatment levels. However, there was no obvious difference between treatments (Figure 1).

IAA concentration $(87.3 \mathrm{pmol} / \mathrm{g}$ fw) in $Q$. serrata roots was comparable with that of rice $(82.1 \mathrm{pmol} / \mathrm{g} \mathrm{fw})$ [18]. IAA concentration in in vitro cultured shoots of $Q$. robur was about 300 to $700 \mathrm{nmol} / \mathrm{g}$ dry weight (dw) in basal area and about 10 to $70 \mathrm{nmol} / \mathrm{g} \mathrm{dw}$ in apical section [20]. IAA concentration in roots of $Q$. serrata was about 82 to $88 \mathrm{pmol} / \mathrm{g}$ fw in the present study, so the IAA concentration in $Q$. serrata roots was very low compared with that of $Q$. robur shoots. The IAA level in roots treated with $\mathrm{Al}$ remained at the same level as that of the pretreatment sample until 2 days after 1-h treatment (Figure 2(a)). In this study, the amount of metabolic intermediate of degradation of IAA, was also determined to assess turnover of IAA. IA-Asp was not detected in the Al-treated roots even after 2 days (Figure 2(b)). IAA concentration in Ca-treated roots decreased by approxi- mately $50 \% 2$ days after treatment. As IAA level decreased, IA-Asp concentration increased in Ca-treated roots (Figure 2(b)). Other metabolic intermediate of degradation of IAA, such as IA-Ala, IA-Ile, IA-Leu, IA-Trp and IA-Phe, were not detected in both treatments.

We detected 17 cytokinin species (data was not shown), including active cytkinins such as N6-( $\triangle 2$ isopentenyl)-adenine (iP) and trans-zeatin (tZ) (Figures 2(c) and (d)). There were not clear difference between $\mathrm{Al}$ and $\mathrm{Ca}$ treatment in both active cytokinins, but the total amount of cytokinins in Ca-treated roots gradually increased to approximately $1.79 \mathrm{pmol} / \mathrm{g}$ fw at 3 days after treatment. The total level of active cytokinins in Altreated roots was lower than that of Ca-treated roots, especially on day 3 (Figures 2(c) and (d)).

\section{Discussion}

To elucidate the stimulatory effect of $\mathrm{Al}$ on lateral root development in an early stage, in this study we focused on in vitro NR activity and the phytohormones such as auxin and cytokinins.

Previously, we reported that rhizospheric $\mathrm{Al}$ enhanced NR activity measured using an in vivo system and increased lateral root primordia in 2-year-old $Q$. serrata seedlings [12]. In the present study, we also confirmed

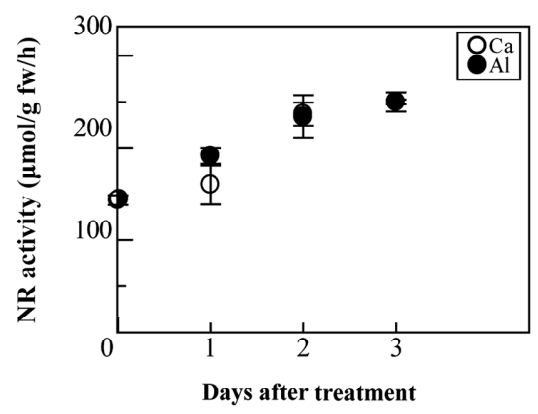

Figure 1. The activity of NR in roots measured by an in vitro system at 0 (Pre), 1, 2, and 3 days after treatment with $2.5 \mathrm{mM} \mathrm{AlCl}_{3}$ (pH 4.0) (Al) or $4.2 \mathrm{mM} \mathrm{CaCl}_{2}$ (pH 4.0) (Ca) for $1 \mathrm{~h}$. Vertical bars represent the means $\pm \mathrm{SE}(\mathrm{n}=3)$.

Table 1. Length of first and second lateral roots and number of second lateral roots at 0 (Pre) and 7 days after treatment. Roots of 8-week-old seedlings were treated with $2.5 \mathrm{mM} \mathrm{AlCl}_{3}(\mathrm{pH} 4.0)$ or $4.2 \mathrm{mM} \mathrm{CaCl}_{2}(\mathrm{pH} 4.0)$ solution for $1 \mathrm{~h}$ and then replaced with freshly prepared nutrient solution.

\begin{tabular}{|c|c|c|c|c|c|}
\hline \multirow{4}{*}{ Treatment } & \multirow{2}{*}{\multicolumn{2}{|c|}{$\begin{array}{c}\text { First lateral roots } \\
\text { Length }\end{array}$}} & \multicolumn{3}{|c|}{ Second lateral roots } \\
\hline & & & \multicolumn{2}{|c|}{ Length } & \multirow{2}{*}{$\begin{array}{c}\text { Number } \\
\text { After } 7 \text { days }\end{array}$} \\
\hline & Pre & After 7 days & Pre & After 7 days & \\
\hline & $(\mathrm{cm})$ & $(\mathrm{cm})$ & $(\mathrm{cm})$ & $(\mathrm{cm})$ & (number/cm) \\
\hline $\mathrm{Al}$ & $25.5 \pm 2.1$ & $28.4 \pm 3.0$ & $2.62 \pm 0.23$ & $4.45 \pm 0.33^{* *}$ & $2.5 \pm 0.3^{* *}$ \\
\hline $\mathrm{Ca}$ & $25.4 \pm 2.4$ & $27.5 \pm 3.0$ & $2.29 \pm 0.12$ & $2.58 \pm 0.31$ & $1.7 \pm 0.2$ \\
\hline
\end{tabular}

Values are the means $\pm \mathrm{SE}(\mathrm{n}=20)$. Asterisks indicate significant differences between Al treatment and Ca treatment $(p<0.01)$ according to the $t$-test. 


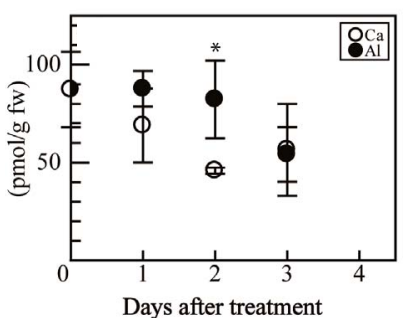

(a)

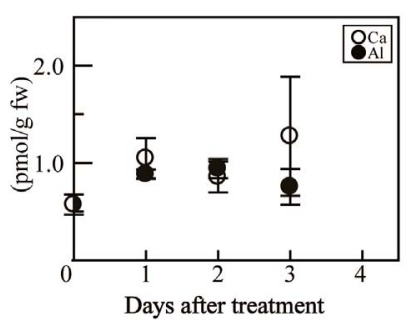

(c)

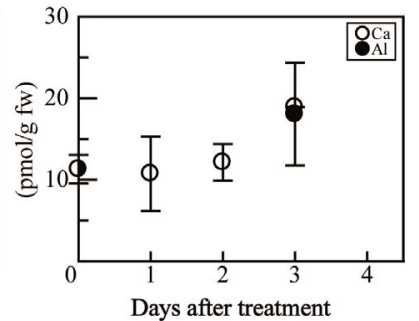

(b)

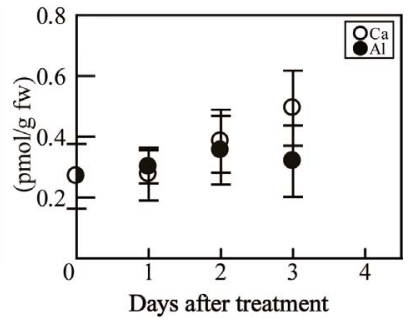

(d)
Figure 2. Concentration of phytohormones: IAA (a), IAAsp(b), iP(c), and $t Z$ (d) in roots at 0 (Pre), 1, 2, and 3 days after treatment. Roots of 8-week-old seedlings were treated with $2.5 \mathrm{mM} \mathrm{AlCl}_{3}$ (pH 4.0) or 4.2 $\mathrm{mM} \mathrm{CaCl}_{2}$ (pH 4.0) solution for $1 \mathrm{~h}$ and then replaced with freshly pre- pared nutrient solution. Vertical bars represent the means \pm SE $(n=$ 3). Asterisks indicate significant differences between Al treatment and Ca treatment $(p<0.05)$ according to the t-test.

that $\mathrm{Al}$ treatment enhanced NR activity in roots measured using an in vitro system and was detected 1 day after $1-\mathrm{h}$ $2.5 \mathrm{mM} \mathrm{Al}$ treatment (Figure 1). The activity of NR in roots treated with $2.5 \mathrm{mM} \mathrm{Al}$ was slightly higher than that of root treated $4.2 \mathrm{mM} \mathrm{Ca}$ after a day from 1-h treatment, however, it did not show clear differences between $\mathrm{Al}$ and $\mathrm{Ca}$ treatments after 2 and 3 days (Figure 1). Both $\mathrm{Al}$ and $\mathrm{Ca}$ are able to reduce the surface potential and neutralize negative surface charge by binding to membrane phospholipids $[21,22]$. In our previous study, the uptake of $\mathrm{NO}_{3}^{-}$by roots from the cultivation medium was enhanced at 3 days after $\mathrm{Al}$ treatment, which was considered to be a result of an increase in positive charge on root cell membrane [12]. Thus, it is considered that enhancement of NR activity induced by $1 \mathrm{~h}$ treatment with $\mathrm{Al}$ or $\mathrm{Ca}$ may be involved in an increase in $\mathrm{NO}_{3}^{-}$influx, caused by an increase in positive charge on the cell membrane due to absorption of $\mathrm{Al}^{3+}$ or $\mathrm{Ca}^{2+}$. Moreover, these observations support our previous hypothesis that enhancement of NR activity in Al-treated roots may be induced by promotion of $\mathrm{NO}_{3}^{-}$uptake due to a change in the surface polarity of the cell membrane.

The growth hormone auxin has many roles in plant development [15]. It plays a central role in cell growth, gravitropism, apical dominance, lateral root initiation, leaf abscission, vascular differentiation, flower bud formation, and fruit development $[15,23]$. In this study, we succeeded in determining the concentrations of IAA and a metabolic intermediate of degradation of IAA (IA-Asp). IAA concentration in Al-treated roots was kept at the same level as in pretreated roots, and IA-Asp was not detected 1 and 2 days after 1-h Al treatment, whereas IAA concentration in roots treated with $\mathrm{Ca}$ for $1 \mathrm{~h}$ decreased and a relatively high amount of IA-Asp was detected at all stages (Figure 2(b)). This result indicates that IAA concentration is maintained at more than 82 $\mathrm{pmol} / \mathrm{g}$ fw in Al-treated roots because Al may limit irreversible inactivation or metabolic degradation of IAA. The concentration of each active cytokinin species did not show an obvious tendency to vary between treatments (Figures 2(c) and (d)). The mechanisms of nitrogen assimilation and nitrogen acquisition which involves plant hormones have been shown, and it has reported that endogenous or exogenous cytokinin took part in process of NR activation [24]. In this study, there was not clear relationship between $\mathrm{iP}$ or $\mathrm{tZ}$ and $\mathrm{NR}$ activity in root after 1-h Al or $\mathrm{Ca}$ treatment. At present, the physiological role of individual cytokinin species involving NR activity and root development in an early stage cannot be explained in Q. serrata.

In general, cytokinins and auxin act antagonistically in controlling meristem activities [25]. Moreover, the level of IAA concentration required to promote growth in each tissue is different [23]. As mentioned above, the IAA in Al-treated roots was kept at about $80 \mathrm{pmol} / \mathrm{g}$ fw for at least 2 days, in contrast to the decrease in Ca-treated roots. The ration of IAA to sum of $\mathrm{iP}$ and $\mathrm{tZ}$ tended to decrease with time after both $1 \mathrm{~h}$-treatments, and the ratio was higher in $\mathrm{Al}$ treatment than in Ca treatment (Figure 3). Enhanced root elongation and increased number of

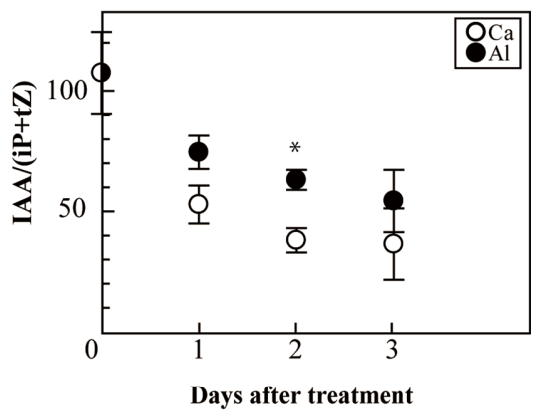

Figure 3. The ration of IAA to sum of $i P$ and $t Z$ in roots at 0 (Pre), 1, 2, and 3 days after treatment. Roots of 8-week-old seedlings were treated with $2.5 \mathrm{mM} \mathrm{AlCl}_{3}$ (pH 4.0) or 4.2 $\mathrm{mM} \mathrm{CaCl}_{2}$ (pH 4.0) solution for $1 \mathrm{~h}$ and then replaced with freshly prepared nutrient solution. Vertical bars represent the means \pm SE $(n=3)$. Asterisks indicate significant differences between Al treatment and Ca treatment $(p<0.05)$ according to the $t$-test. 
second lateral roots induced by $\mathrm{Al}$ in the present study (Table 1) may result in $\mathrm{Al}$ maintaining IAA concentration, and the hormone balance (auxin/cytokinin ratio) may be essential for efficient lateral root development.

A close relationship between auxin-induced lateral root formation and NO-induced lateral root development has been reported recently. Initiation of lateral roots is accompanied by an increase in NO level, an increase that is involved with auxin signaling [13]. Furthermore, Kolbert et al. [14] reported that lateral root development by auxin-induced NO production was associated with NR activity. In the present study, the 1-h Al treatment enhanced NR activity in roots and the elongation and development of second lateral roots, but 1-h Ca treatment did not enhance second lateral root growth even though NR activity increased (Figure 1 and Table 1).

Al-induced enhancement of root growth in Q. serrata may be caused by stimulation of NR activity in roots and IAA-induced NO synthesis. Furthermore, these data, including those on phytohormones, might be useful for further investigation of tree development.

\section{Acknowledgements}

This work was supported by Grants-in-Aid for Young Scientists (B) (20780114) from the Ministry of Education, Sports, Culture, Science and Technology of Japan, and The Salt Science Research Foundation.

\section{REFERENCES}

[1] G. R. Gobran and S. Clegg, "A Conceptual Model for Nutrient Availability in the Mineral Soil-Root System," Canadian Journal of Soil Science, Vol. 76, No. 2, 1996, pp. 125-131. doi:10.4141/cjss96-019

[2] A. Göttelin, A. Heim and E. Matzner, "Mobilization of Aluminium in the Rhizosphere Soil Solution of Growing Tree Roots in an Acid Soil," Plant and Soil, Vol. 211, No. 1, 1999, pp. 41-49. doi:10.1023/A:1004332916188

[3] W. H. Smith and A. S. Pooley, "Red Spruce Rhizosphere Dynamics: Spatial Distribution of Aluminum and Zinc in the Near-Root Soil Zone," Forest Science, Vol. 35, No. 4, 1989, pp. 1114-1124.

[4] T. Ohno, "Rhizosphere $\mathrm{pH}$ and Aluminum Chemistry of Red Oak and Honeylocust Seedlings," Soil Biology and Biochemistry, Vol. 21, No. 5, 1989, pp. 657-660.

[5] R. B. Clark, "Effect of Aluminium on Growth and Mineral Elements of Al-Tolerant and Al-Intolerant Corn," Plant and Soil, Vol. 47, No. 3, 1977, pp. 653-662. doi:10.1007/ BF0001 1034

[6] T. B. Kinraide, "Aluminum Enhancement of Plant Growth in Acid Rooting Media. A Case of Reciprocal Alleviation of Toxicity by Two Cations," Physiologia Plantarum, Vol. 88, No. 4, 1993, pp. 619-625.

doi:10.1111/j.1399-3054
[7] R. Tomioka, A. Oda and C. Takenaka, "Root Growth Enhancement by Rhizospheric Aluminum Treatment in Quercus serrata Thunb Seedlings," Journal of Forest Research, Vol. 10, No. 4, 2005, pp. 319-324. doi:10.1007/s10310-005-0152-0

[8] F. C. Thornton, M. Schaedle and D. J. Ryanal, "Effect of Aluminum on the Growth of Sugar Maple in Solution Culture," Canadian Journal of Forest Research, Vol. 16, No. 5, 1986, pp. 892-896. doi:10.1139/x86-159

[9] J. Huang and E. P. Bachelard, "Effect of Aluminum on Growth and Cation Uptake in Seedlings of Eucalyptus mannifera and Pinus radiate," Plant and Soil, Vol. 149, No. 1, 1993, pp. 121-127. doi:10.1007/BF00010769

[10] T. Mossor-Pietraszewska, "Effect of Aluminium on Plant Growth and Metabolism," Acta Biochimica Polonica, Vol. 48, No. 3, 2001, pp. 673-686.

[11] L. V. Kochian, O. A. Hoekenga and M. Piñeros, "How Do Crop Plants Tolerate Acid Soils? Mechanisms of Aluminum Tolerance and Phosphorous Efficiency," Annual Review of Plant Biology, Vol. 55, 2004, pp. 459-493. doi:10.1146/annurev.arplant.55.031903.141655

[12] R. Tomioka, A. Uchida, C. Takenaka and T. Tezuka, "Effect of Aluminum on Nitrate Reductase and Photosynthesis Activities in Quercus serrata Seedlings," Environmental Sciences, Vol. 14, No. 3, 2007, pp. 157-165.

[13] N. Correa-Aragunde, M. Graziano and L. Lamattina, "Nitric Oxide Plays a Central Role in Determining Lateral Root Deveropment in Tomato," Planta, Vol. 218, No. 6, 2004, pp. 900-905, doi:10.1007/s00425-003-1172-7

[14] Z. Kolbert, B. Bartha and L. Erdei, "Exogenous AuxinInduced NO Synthesis is Nitrate Reductase-Associated in Arabidopsis thaliana Root Primordial," Journal of Plant Physiology, Vol. 165, No. 9, 2008, pp. 96-975. doi:10.1016/j.jplph.2007.07.019

[15] Y. Zhao, "Auxin Biosynthesis and Its Role in Plant Development," Annual Review Plant Biology, Vol. 61, 2010, pp. 49-64. doi:10.1146/annurev-arplant-042809-112308

[16] H. Sakakibara, "Cytokinins: Activity, Biosynthesis, and Translocation," Annual Review Plant Biology, Vol. 57, 2006, pp. 431-449. doi:10.1146/annurev.arplant.57.032905.105231

[17] R. H. Hageman and A. J. Reed, "Nitrate Reductase from Higher Plants," Methods in Enzymology, Vol. 69, 1980, pp. 270-280.

[18] M. Kojima, T. Kamada-Nobusada, H. Komatsu, K. Takei, T. Kuroha, M. Mizutani, M. Ashikari, M. Ueguchi-Tanaka, M. Matsuoka, K. Suski and H. Sakakibara, "Highly Sensitive and High-Throughput Analysis of plant Hormones using MS-Probe Modification and Liquid Chromatography-Tandem Mass Spectrometry: An Application for Hormone Profiling in Oryza sativa.," Plant Cell Physiology, Vol. 50, No. 7, 2009, pp. 1201-1214. doi:10.1093/pcp /pcp057

[19] K. Yamamoto, "Estimation of the Canopy-Gap Size Using Two Photographs Taken at Different Heights," Ecological Research, Vol. 15, No. 2, pp. 203-208. doi:10.1046/j.1440-1703.2000.00341.x 
[20] N. Vida, G. Arellano, M. C. San-Jose, A. M. Vieitez and A. Ballester, "Developmental Stages during the Rooting of in-Vitro-Cultured Quercus robur Shoots from Material of Juvenile and Mature Origin," Tree Physiology, Vol. 23, No. 18, 2003, pp. 1247-1254. doi:10. 1093/treephys/23.18.1247

[21] P. M. Macdonald and J. Seelig, "Calcium Binding to Mixed Phosphatidylglycerol-Phosphatidylcholine Bilayers as Studied by Deuterium Nuclear Magnetic Resonance," Biochemistry, Vol. 26, 1987, pp. 1231-1240.

[22] M. A. Akeson, D. N. Munns and R. G. Burau, "Adsorption of $\mathrm{Al}^{3+}$ to Phosphatidylcholine Vesicle," Biochimica et Biophysica Acta (BBA)-Biomembranes, Vol. 986, No. 1, 1989, pp. 33-40.
[23] L. Taiz and E. Zeiger, "Auxin: the Growth Hormone," In: L. Taiz and E. Zeiger, Eds., Plant Physiology, Sinauer Associates Inc., Sunderland, 2006, pp. 467-507.

[24] G. Krouk, S. Ruffel, R. A. Gutiérrez, A. Gojon, N. M. Crawford, G. M. Coruzzil and B. Lacombe, "A Framework Integrating Plant Growth with Hormones and Nutrients," Trends in Plant Science, Vol. 16, No. 4, 2011, pp. 178-182, doi:10.1016/j.tplants.2011.02.004

[25] L. Moubayidin, R. D. Mambro and S. Sabatini, "Cytokinin-Auxin Cross Talk," Trends in Plant Science, Vol. 14, No. 10, 2009, pp. 557-562. doi:10.1016/j.tplants.2009.06.010 